\title{
MUCOSAL HEALING IN PEDIATRIC ULCERATIVE COLITIS - EXPERIENCE OF A ROMANIAN CENTER OF PEDIATRIC GASTROENTEROLOGY
}

\author{
Authors: Lesanu Gabriela 1,2, Becheanu Cristina 1,2, Smadeanu Roxana 1,2, Andronie Irina ${ }^{2}$, Mitea Gabriela ${ }^{2}$ \\ 1 "Carol Davila" University of Medicine and Pharmacology \\ 2 "Grigore Alexandrescu" Emergency Children's Hospital
}

\section{Background and Aims}

Mucosal healing became a target of therapy in inflammatory bowel disease.The aim of the study was to evaluate the outcome of long-term maintenance treatment in pediatric ulcerative colitis

Materials and methods: Medical records of patients with PUC (pediatric ulceratie colitis) between 2005-2016 were analysed. We collected demographic and clinical data, fecal calprotectine values, histological exams and data about maintenance therapy. The patients with stable remission (for at least one year) were divided in two groups: (1) mucosal healing (persistent fecal calprotectine $<100 \mathrm{ug} / \mathrm{g} \pm$ histological remission) and (2) clinical remission.

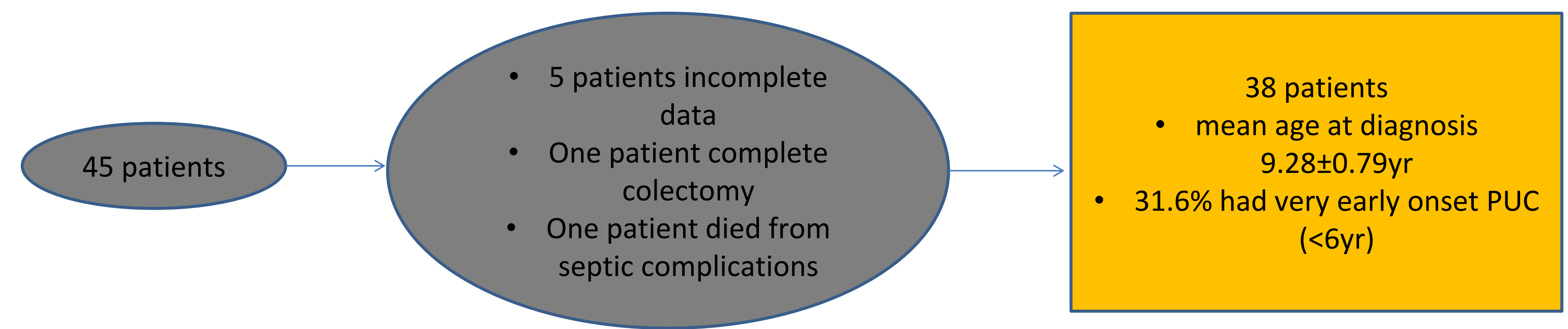

\section{MUCOSAL HEALING GROUP}

- $52.6 \%$ of patients

- mean age at diagnosis $9.36 \pm 1.09 \mathrm{yr}$,

- $45 \%$ - histological remission

- $30 \%$ younger than 6 years

- All patients were compliant to treatment

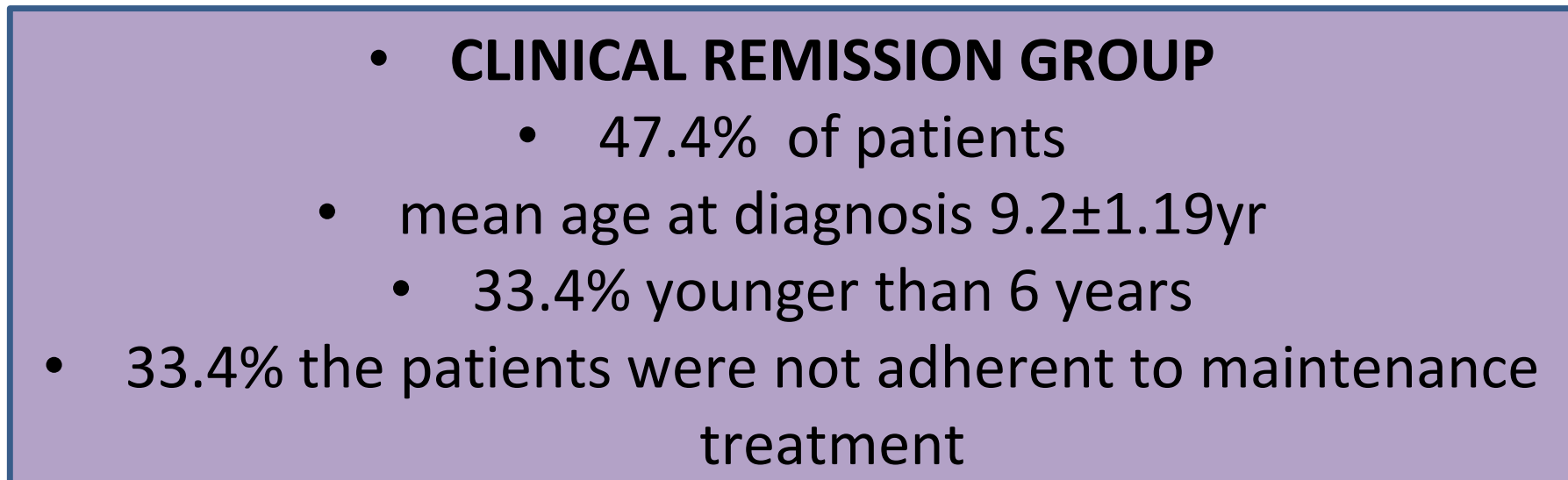

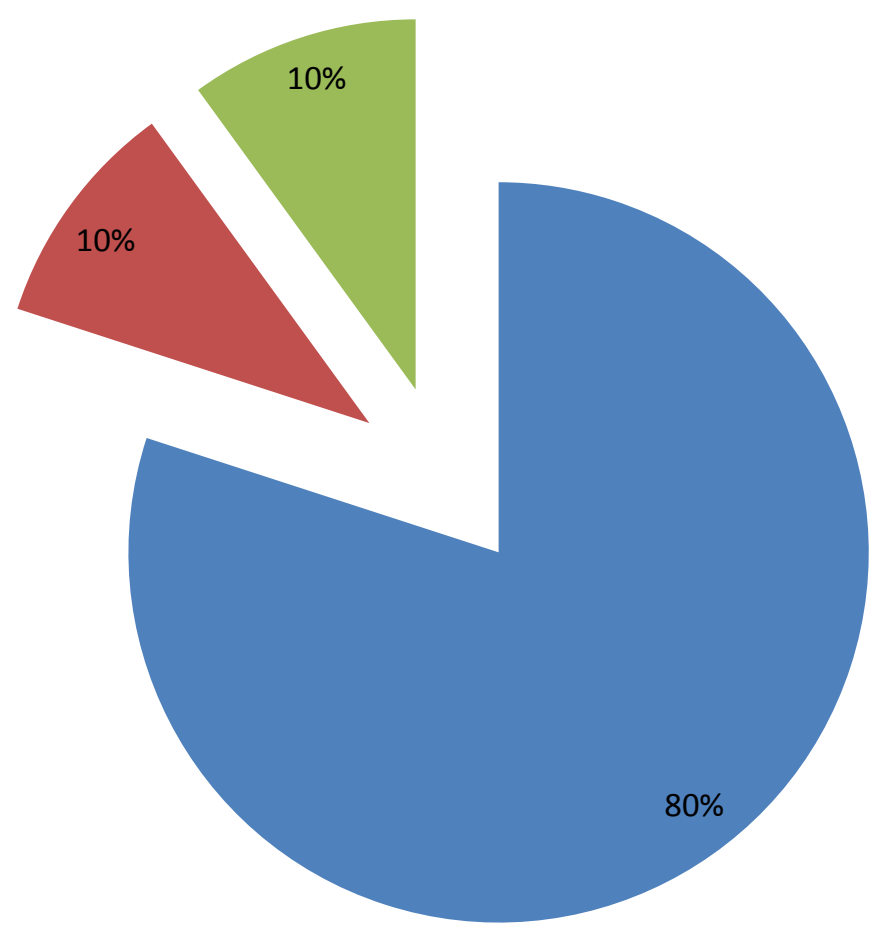

- 5-ASA

- immunomodulators

mbiological agents

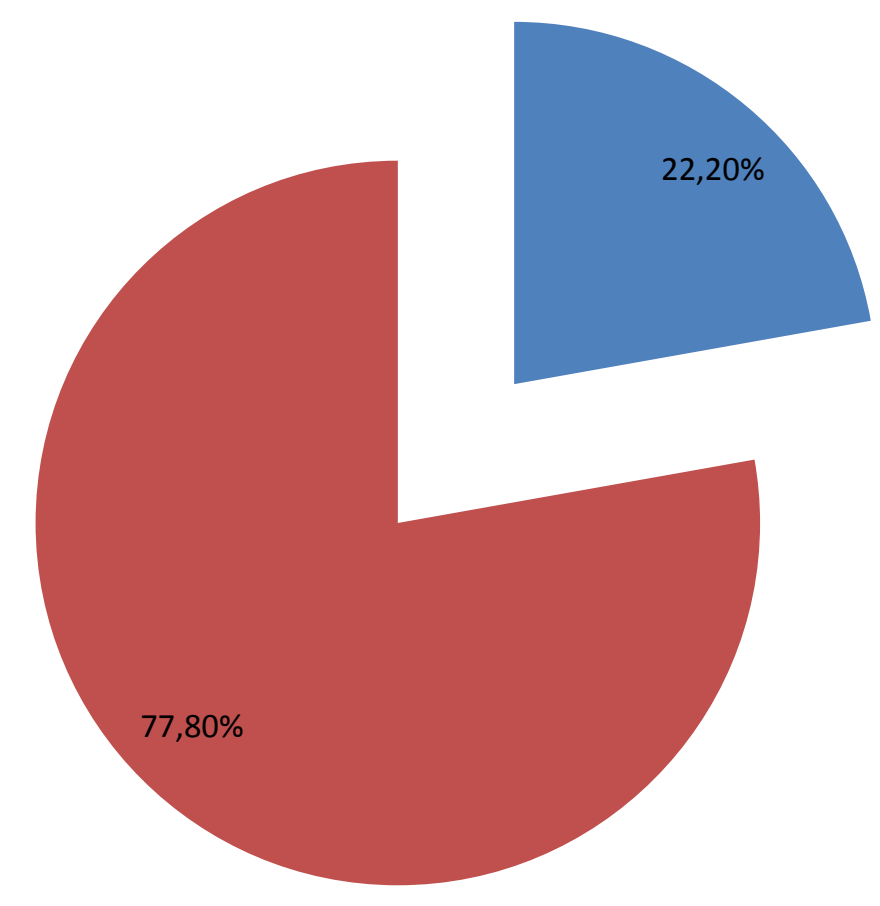

immunomodulators $\quad$ 5-ASA

\section{Conclusion:}

1. More than one half of the patients achieved mucosal healing.

2. Treatment with biological agents was associated with mucosal healing in all patients. Restriction of using biological agents due to age ( $<6$ years) resulted in a lower rate of mucosal healing in this age group.

3. Non-compliance to maintenance therapy was associated with failure to achieve mucosal healing. 